\title{
Applications and Recent Development of DTMF Based Technology in Home Automation
}

\author{
Ayodele S. Oluwole, O. P. Odekunle, and E. Olubakinde
}

\begin{abstract}
Recent technological advancements have made things in an efficient manner. This paper presents the overall design of Dual-tone multi-frequency (DTMF) signaling with little cost and establishes a new pattern for home automation developments. The benefits of a DTMF system is that it may be controlled remotely from afar, effectively saves energy, minimizes human stress. One of the most developing trends in home appliance control innovation is DTMF-based home automation technology using Arduino. In order to make this project work, an Arduino Uno was used. This is primarily about the ATmega328 microcontroller (MCU). It comprises of 14 digital output/input pins, analogue inputs of about 6 ports, a USB port for programming the onboard microcontroller, an ICSP header, a power jack, and a reset button. DTMF can be realized using numerous approaches for example, Discrete Fourier Transform (DFT), and Genetic Algorithm (GA). These techniques are generally analyzed using MATLAB, GUI, and FPGAs. DFT procedure has the shortcoming of power overwhelming and necessitates supplementary hardware. The system design in this project work was implemented with $\mathrm{C}++$ programming languages on the Arduino IDE software. The circuit diagrams were modeled using the use of Proteus software.
\end{abstract}

Index Terms - Arduino, Bluetooth, DTMF Decoder, Home Automation System, Relays.

\section{INTRODUCTION}

Currently, we have come into the age of fast and effortless technology. In the olden days, Manual operations were wellknown and well-executed in the past. Home automation is gaining momentum around the world and is being widely used [1], [2]. With the help of contemporary technology, the home automation procedure allows everything to be controlled automatically [3].Home automation is in charge of the house's operations. We propose a unique System of applications in this project, as well as recent developments in DTMF-based technology in home automation [4].

Dual-tone multi-frequency (DTMF) signaling is an in-band telecommunication signaling system that uses the voicefrequency band to communicate with telephone equipment, other communications devices, and switching centers through telephone lines.

Beginning in 1963, DTMF was developed in the Bell system in the United States and became known as TouchTone for use in push-button telephones provided to telephone consumers [5], [6].

In analog telephone dialing, data entry, voice mail systems, and remote control of different consumer products, DTMF signaling is widely utilized (auto answering machines, home automation devices, bank information services, etc.).

This system can be operated from a far distant. It's a wireless system, but rather than using a separate wireless module (transmitter and receiver), we're employing cell phones. The cell phone-operated system has a wide range of applications (service provider range), there is less chance of interference because each call has its own unique frequency, and it also has more control keys. The decoding of DTMF tone is the basis for cell phone-controlled systems. Dual Tone Multi Frequency (DTMF) is an acronym for Dual Tone Multi Frequency. The DTMF Decoder, Arduino UNO, and relay module are the key components in this project. We were able to monitor and control numerous home appliances using the interconnection of these components and the usage of a cell phone as a remote [7-9]. This proposed system steers the evolution of home automation in a new direction.

The remainder of this paper is organized as follows. DTMF decoder, Arduino Uno (ATMEGA328), Arduino Uno Architecture, and Arduino Uno Communication for DTMF are introduced in section 2. In section 3, the GSM module (SIM $800 \mathrm{~L}$ ) with its array is analyzed. Thereafter, section 4 provides simulation results to verify the performance of the proposed method. Finally, section 5 concludes the paper.

\section{LITERATURE SURVEY}

A home automation system is a channel by which homeowners and occupants have control over a variety of electrical and electronic appliances in their household. The home automation system is the use of mechatronics and computer technologies to household appliances by defining the home automation as domestics [10]. A home automation system provides all of its clients, especially forgetful ones, with the benefit of being able to manage and track energy usage at home or while away, ensuring that superfluous equipment are turned off as needed to cut energy consumption. Convenience is what makes the Dual Tone Multi Frequency Based home automation using GSM Module interesting in that one does not have to go home and turn $\mathrm{ON}$ the air conditioner and wait for the environment to get cool, while still at work one can turn ON the geyser to ensure that once they are home the water is warm enough and ready to be used [10]. This saves time and it is very convenient. When energy consumption issue arises, the emphasis is that there is an inevitable need to conserve energy with the means possible. The major cause of energy
Submitted on May 16, 2021.

Published on June 20, 2021.

A. S. Oluwole, Federal University Oye-Ekiti, Nigeria

(corresponding e-mail: ayodele.oluwole@fuoye.edu.ng)
O. P. Odekunle, Federal University Oye-Ekiti, Nigeria

(e-mail: preciousodekunle@ gmail.com)

E. Olubakinde, Federal Polytechnic, Ile-Oluji, Nigeria.

(e-mail: enisolu@gmail.com). 
consumption is the inability to remotely monitor and control appliances. Then there's Dual Tone Multi Frequency Based Home Automation with GSM Module, which is one of the better options because it allows the system to be controlled from anywhere in the globe, and GSM uses SMS commands to operate the appliances. The GSM and DTMF is used for communication where there is no internet connectivity. A receiver, transmitter, and an Input/Output device, and a controlling unit are all included in each appliance node (Microcontroller). DTMF Based Home Automation is used for its high availability, coverage, but it suffers from the SMS and GSM costs and the relative dependency of the SMS on the network [11].

\section{RELATED WORKS}

Hassan, et al [12] designed a GSM based automatic motor control and protection system. The design suggested a microcontroller based three way controlled highly secured door using DTMF and GSM Technology. The system operations are managed by intelligent code within the microcontroller, GSM, DTMF technology. The door was designed and constructed for the industrial control room, the emergency door, the secret gate, the main door of any agency, the safe room, the storeroom and, basically the restricted entry. The gate could be managed in three ways, e.g. by mobile phone using an SMS or click, a toggle and a keypad code. The camera was used at the top of the door to identify a visitor or a knocker and to track him or her from the room. The design's objectives were mainly to produce a low-cost, reliable, ubiquitously available, self-configured, remotely controlled door automated system.

Ashwini, et al [13] designed a Dual Tone Multi Frequency (DTMF) based home automation system using microcontroller with portable power supply. These were the summary of its operation: When the user at any place pushes a key of his mobile phone, a corresponding DTMF tone is generated which is transmitted to the mobile phone at home. The decoder table is referred while decoding the DTMF tone received at the receiver depending upon its frequency and corresponding device is either switched ON or Off depending on the command given by the user. The system is portable since it is accompanied by a variable power supply. The following are its drawbacks:

- Security issues may arise since any unauthorized person can access the devices at home.

- Absence of feedback will result in uncertainty of whether the task is performed or not on pressing the corresponding key.

Wakas and Waseem [11] designed a project Dual Tone Multi Frequency (DTMF) home automation. This project enabled users to remotely control their home appliances and systems using a cell phone-based interface. It ensured the user sent an authentication code along with a required / desired function / to his/her name so as to have access to the control system via the Dual Tone Multi Frequency (DTMF).The project made use of electrical components e.g DTMF decoder IC MT8870, Resistors (100 $\Omega ; 100 \mathrm{k} \Omega ; 70 \mathrm{k} \Omega ; 390 \mathrm{k} \Omega$ ), Capacitors ( $0.1 \mu \mathrm{Fx} 2)$, Crystal oscillator $(3.579545 \mathrm{MHz})$, IC 7474 D flip flop, BC547 Transistor, 6V Relay. The following were its drawbacks:
- Security issues may arise since any unauthorized person can access the devices at home.

- Absence of feedback will result in uncertainty of whether the task is performed or not on pressing the corresponding key.

- The system needs a cell phone to be placed in circuit.

Choudhari and Rucha [14] presented a paper that focused on the design of home automation system using Dual Tone Multi Frequency. The system consists of ATmega8 microcontroller, Dual Tone Multi Frequency decoder (HT9107B), IC and a mobile phone. The system made use of bulbs to indicate the DTMF actions carried out in the system. The system explained that once the cell phone headset (headphone) jack is connected to the mobile phone, then the mobile would control the bulbs (turn ON or OFF) during the call by pressing the DTMF keys on the user's phone which would then control the bulbs.

Asadul et al [15] research work designed a home automation system using Dual Tone Multi Frequency (DTMF). The design uses the Dual Tone Multi Frequency (DTMF) technique used in touch tone telephones, to control multi electronic devices from long distances using the mobile phones. The system made use of the DTMF technology to operate several electronic gadgets over a long distance using a cell phone. The system allowed the user to control and monitor the current state of home appliances using a cell phone. This was accomplished by sending a signal from a cell phone (control phone) to another cell phone in the house (home-based phone). The cell phone was connected to an interface circuit that detects DTMF signals and to grants access to the control unit that controls and monitors the home appliances.

Mamunoor and Mehdi [16] presented a paper in which a DTMF Based Home Appliances Control Using Cell Phone system was developed. The system enables users to remotely control their home appliances from any part of the world. The project made use of electrical components e.g DTMF decoder IC MT8870, Transistor (BD135), Microcontroller (PIC16F73), Relay and Cell phone, etc. The following were its drawbacks:

- Security issues may arise since any unauthorized person can access to the devices.

- Absence of feedback will result in uncertainty of whether the task is performed or not on pressing the corresponding key.

Rangkuti and Simatupang [17] proposed and presented a paper (journal) Security lock with DTMF polyphonic tone sensor. The authors presented locking automation system using smart phone polyphonic tone sensor. The electrical components used are DTMF decoder, Arduino Uno, etc. The DTMF (Dual Tone Multi Frequency) module was simply programmed with Arduino Uno which was used to receive a polyphonic tone signal embedded in the Smartphone system. Arduino Uno interprets the signal so that the solenoid will automatically unlock the door. After three seconds of delay, the door would be automatically locked again (protection system). The following are the drawbacks of the proposed system:

- such as a low security scheme,

- short working range of tolerance, and 
- limited number of key digits.

Shirsath et al [18] designed an embedded wireless light intensity control using Dual Tone Multi Frequency. The designed a system was used for controlling the AC lamp intensity operation through Mobile phone using DTMF technology. It also offered wireless and continuous power over many household and industrial products. The home automation process works by automatically monitoring everything in the house using DTMF software. The processes involved were as follows; first dial the receiver mobile number, the bell rings, and after a few bell rings, the phone automatically switches to the auto-response mode and switches to the base unit to operate. The electrical components used were 89C51 Microcontroller, DTMF decoder, Lamp, etc. The controller unit of the entire system is the 89C51 Microcontroller. The DTMF decoder decodes the signal and output to the controller device to which the AC lamp is attached. When users need to control the lamp intensity of the user, call the mobile phone that is present at the receiver side when the call is received, as the user needs to press the mobile phone keys assigned to the intensity control of the lamp operation. The drawback of the system was that it suffered from the insecurity problem that is, the system could be controlled from anyone that has access to the telephone line number.

\section{RESEARCH METHOD}

With the help of a DTMF decoder, the received tone is processed. Thereafter, the DTMF decoder sends the signal to the microcontroller, which controls the relay. The number dialed on a push button or DTMF keypad is identified by a signaling system that says the number dialed.

- A system that uses multi-frequency tone dialing transmits the number or key dialed by the caller using push button keypads in phones and mobile phones.

- Long-distance signaling of dialing numbers in the voice frequency range across telephone lines is now possible thanks to DTMF.As the name implies, DTMF represents a key by combining two sine waves tones.

\section{A. Arduino Uno (ATMEGA 328)}

Arduino is a versatile, easy-to-use open source electronics prototyping platform with adaptable hardware and software.It's for artists, designers, electronic enthusiasts, and anyone else who wants to make interactive things or surroundings. The Arduino Uno is based on the ATmega328 microprocessor (MCU).It comprises of 14 digital output/input pins, analogue inputs of about 6 ports, a USB port for programming the onboard microcontroller, an ICSP header, a power jack, and a reset button.It is powered by a 16 $\mathrm{MHz}$ crystal oscillator and contains all of the necessary components to support the MCU.It's incredibly simple to use because all we have to do is connect it to a computer with a USB cable, or power it using a conventional AC-to-DC adapter.

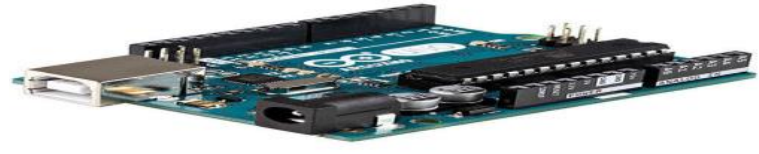

Fig. 1. Arduino Uno.

\section{B. Arduino Uno Architecture}

The Arduino architecture, or more specifically the Arduino IC, is used (ATmega328). The ATmega328 is a low-power CMOS 8-bit microcontroller with a RISC (reduced instruction set computer) architecture that has been modified. The AVR employs Harvard architecture, which includes distinct memories and buses for program and data in order to promote performance and parallelism. A single level of pipelining is used to execute instructions in the program memory. An external $16 \mathrm{MHz}$ Crystal Oscillator controls the clock.

The Arduino Uno's (ATmega328) CPU's basic operation is as follows:

- Data Upload: Data is uploaded in serial via the port (from the Arduino IDE on the microcomputer). The data is decoded, and the instructions are delivered to the instruction register, which decodes them on the same clock pulse as the data.

- The next set of instructions is stored into the instruction register on the following clock pulse.

- The registers in general purpose registers are 8-bit, but there are three 16-bit registers as well.

a. Data for normal calculations and results is stored in 8-bit registers.

b. Data from the timer counter is stored in two registers using 16-bit registers. For example, X-low and X-high. They are quick and are utilized to save certain hardware functions.

- EEPROM: This type of memory stores data indefinitely, even if the power is turned off. It takes a long time to program an EEPROM.

- Interrupt Unit: This determines if an interrupt exists for the execution of ISR instructions (Interrupt Service Routine)

- Serial Peripheral Interface (SPI): This is a bus interface for sending data between microcontrollers and minute peripherals like cameras, displays, and SD cards. It has separate clock and data lines, as well as a select line for selecting which device to communicate with.

- Watchdog timer: This device detects and recovers from MCU failure.

- Analog comparator: This ultimately compares the positive and negative pins $\&$ set input values when the value of the positive output pin is higher.

- Status and control: This is ultimately used to control the flow of command executions by periodically monitoring other blocks inside the CPU.

- ALU (Arithmetic and Logical Unit): The AVR ALU is a high-performance arithmetic and logical unit that communicates directly with all 32 general-purpose working registers. The arithmetic, logical, and bitfunction operations are the three primary kinds of ALU operations categories. 


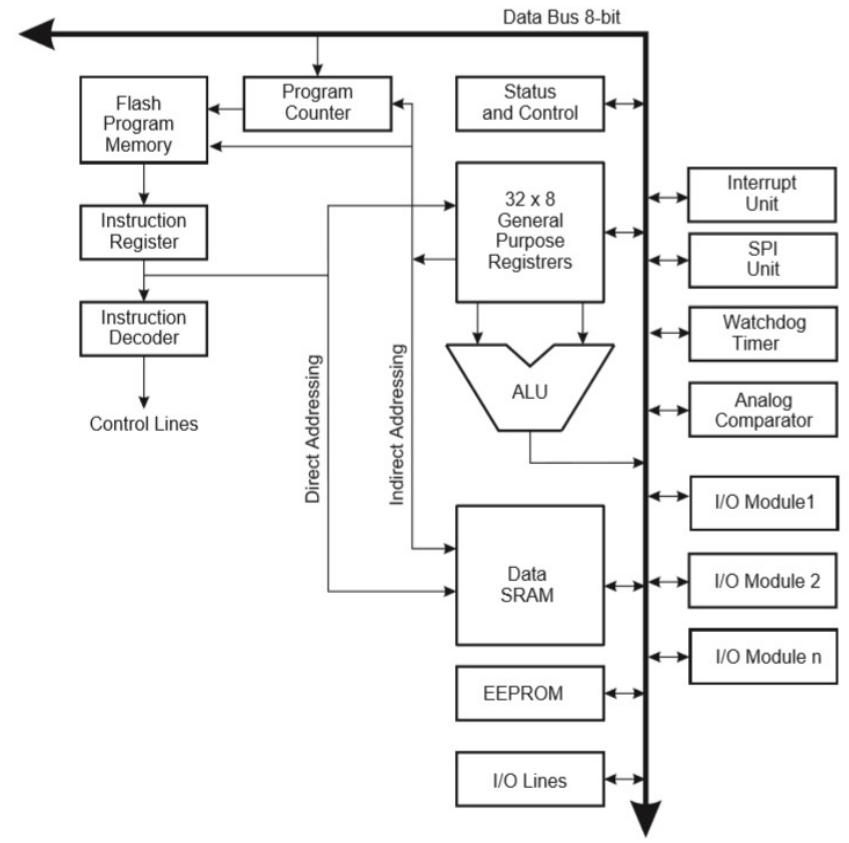

Fig. 2. Functional representation of the Arduino Uno (ATMEGA328).

\section{GSM Module (SIM 800L)}

Many communication devices that employ GSM (Global System for Mobile Communications) technology require GSM modules. It allows a computer to communicate with a GSM network. The GSM module serves as a wireless modem, transmitting and receiving data using radio waves. It allows communication via the available mobile network once it is linked. The AT command set is a collection of machine instructions used to activate functionalities on an intelligent modem when communicating with the GSM.

A PNP transistor connects the GSM modem to the controller. The transmit $(\mathrm{Tx})$ and receive $(\mathrm{Rx})$ pins of the GSM module and the microcontroller must be compatible before the GSM may be interfaced with the microcontroller.

The maximum input voltage to the GSM module's receive pins is 3 volts, whereas the maximum output voltage to the GSM module's transmit pins is around 2volts. In order to assure compatibility, the PNP transistor is used to boost the voltage of the GSM module's transmit pin from around $2 \mathrm{~V}$ to 4-5 V, which is a high logic for the PIC microcontroller's receive pin. The GSM module determines which communication method is most appropriate (SMS, GPRS or DTMF).

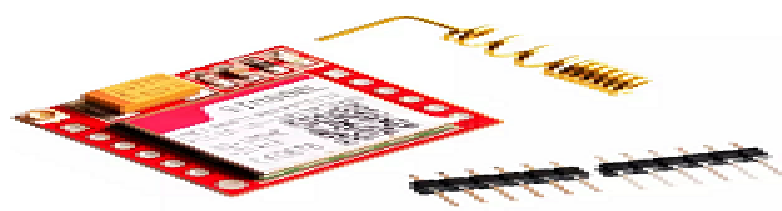

Fig. 3. The GSM Module (SIM 800L).

\section{System Design Operation}

The microcontroller and its working circuits, the power supply and regulator, the LCD, the GSM SIM acknowledgement module, and the relay block make up the system. The Arduino Uno (ATMEGA328) microcontroller is the main control of the system, storing all of the instructions required for the control system to function properly and coordinating the actions of all other components. Sending a call and leaving it to ring for roughly a minute before ending it from the desired mobile device stores a phone number for accessing and receiving feedback status on the memory. The Arduino Uno (ATMEGA328) microcontroller begins by setting up the necessary components, such as the I/O ports and external interrupt. "GSM Configuration DTMF Enabled" appears on the LCD. An external interrupt pin then alerts the Arduino Uno (ATMEGA328) microcontroller to the presence of a valid DTMF code. The microcontroller reads the code from the proper input pins and operates appropriately turning on/off a specific load or reporting the status of the load via SMS feedback. The GSM Module provides and embeds the DTMF signal. The MCU delivers the necessary output signal as a four-bit binary number for the MCU to receive and decode when it detects a valid DTMF input. It additionally pulses its "StD" pin when a valid code is present. Four relays, as well as required components such as transistors and diodes, make up the relay block. The relay's coil is powered by $5 \mathrm{~V}$. The relays' COM (common) pins are linked to the live power input, while the NO (Normally Opened) pins are linked to the terminal block as the corresponding load output connection. This setup prevents a load from turning on without the relevant relay being activated. Thus, after all this has been done without any havoc, then, we can declare our main aim has been achieved.

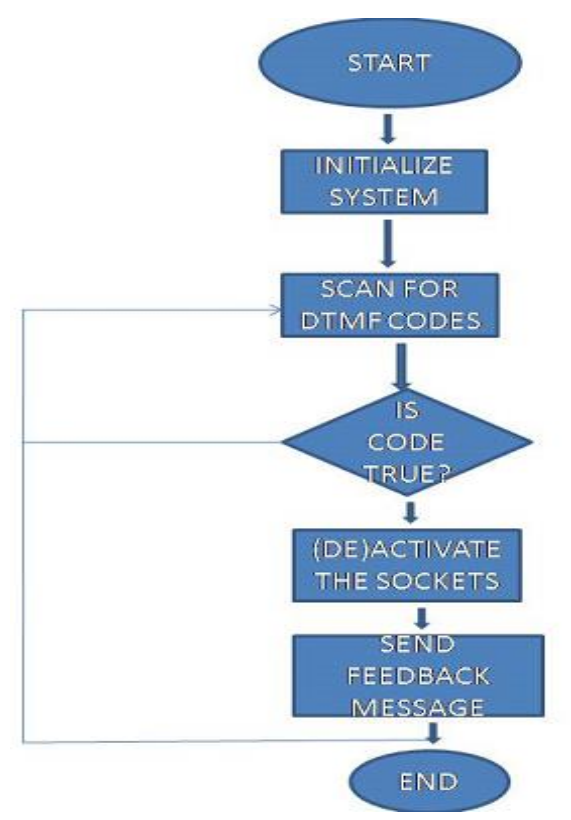

Fig. 4. The Flowchart of the Processes in the Project.

\section{E. Design Analysis}

The Dual Tone Multi Frequency Based Home Automation using GSM Module effectively controls electrical appliances and devices by dialing their separate pre-configured numbers specifically allotted for each load through an accessible communication network. The GSM Module; Microcontroller unit (Arduino Uno); Power supply \& Regulator; and Relay unit are the three key components of this system (Sockets). 


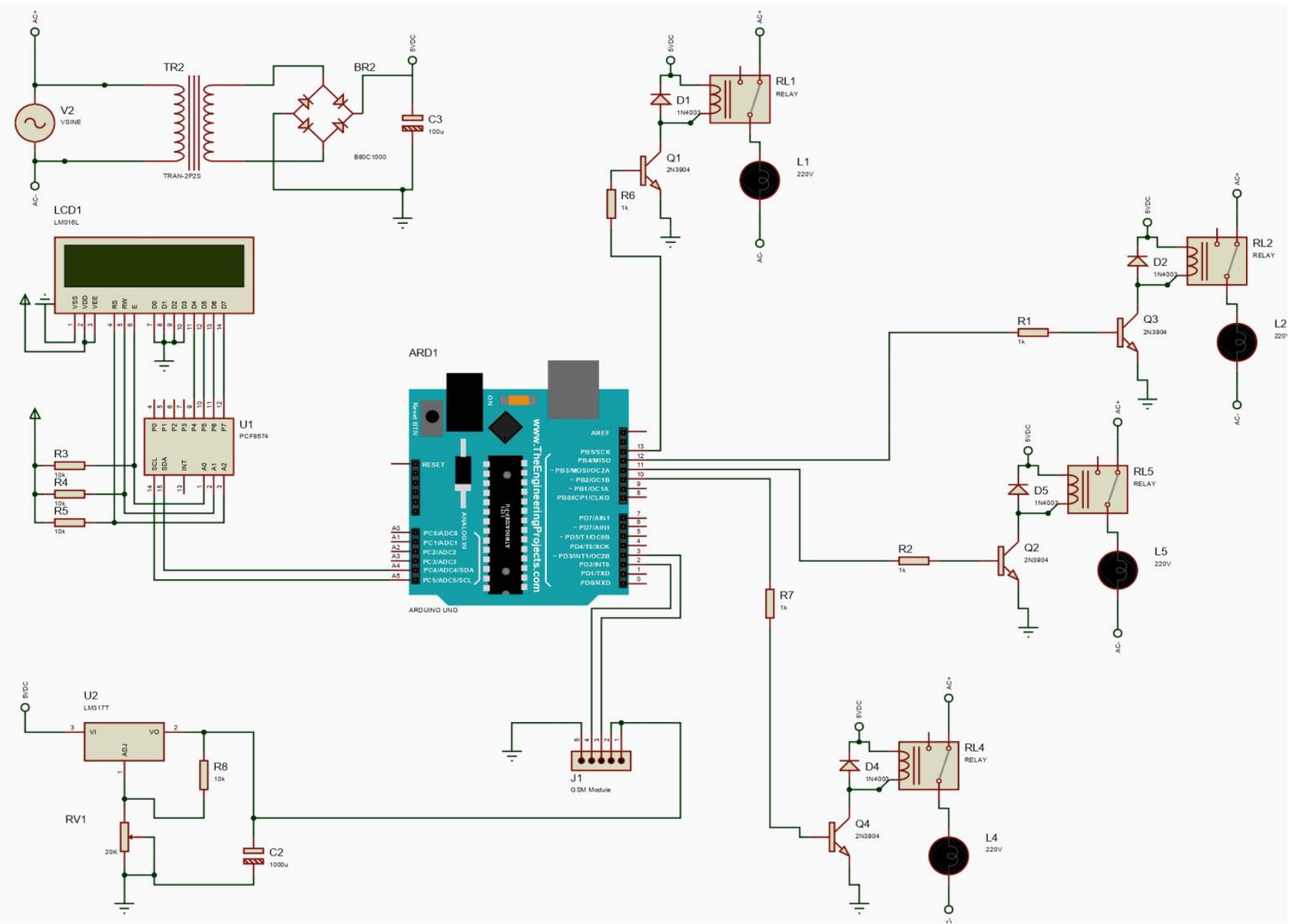

Fig. 5. The DTMF-based Home Automation System Using GSM Module Circuit Diagram.

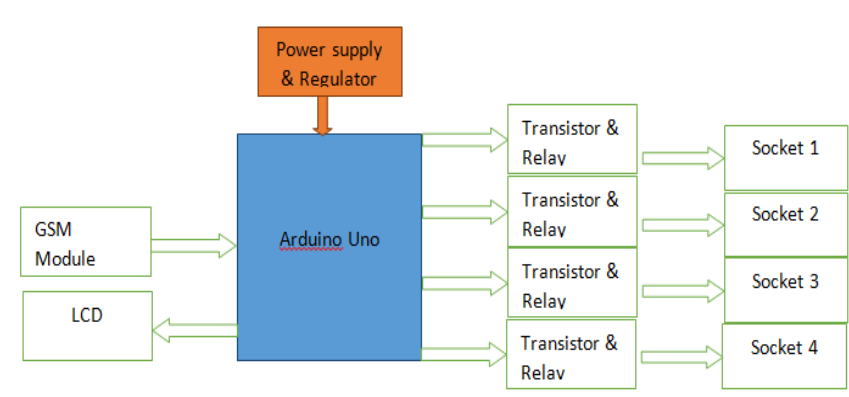

Fig. 6-The DTMF-based Home Automation System Using GSM Module Block Diagram.

\section{F. DTMF Detection}

This is the procedure for detecting DTMF tone signals using a DTMF detector. Any tone signal coming from a frequency that is not the sum of the low and high tones is rejected by the DTMF detector. The DTMF detector helps to prevent DTMF tones from being misinterpreted as noise, interference, or speech. DTMF can be detected using the following using numerous approaches for example, Discrete Fourier Transform (DFT), and Goertzel Algorithm (GA), etc. The respective approaches can be expressed mathematically:

- Discrete Fourier Transform (DFT):

The Discrete Fourier Transform approach uses an aperiodic discrete signal can be represented as the algebraic sum of its frequency components using the DFT. The DFT, has the shortcoming of power overwhelming and necessitates supplementary hardware. The DFT can be expressed mathematically as [19]:

$$
\mathrm{y}\left(w_{0}\right)=\sum_{n=0}^{N-1} y(w) e^{-i w_{0} n}=0 \ldots \ldots N-1
$$

where (n)is the duration finite sequence of the length $\mathrm{N}$, and $w_{0}$ is the normalized frequency in radian, $\mathrm{A}$ is the signal power in watts.

Considering a signal $\mathrm{y}(\mathrm{t})=\mathrm{A} \sin \left(w_{0} t\right)$.

The sample signal will be $\mathrm{y}(\mathrm{n})=\mathrm{A} \sin w_{0} \frac{n}{f_{s}}=A \sin 2 \pi \frac{f}{f_{s}}$.

The Discrete Fourier Transform cumulated formula is represented mathematically as:

$$
\sum_{n=0}^{N-1} y(w) e^{-i \omega n}=0 \ldots \ldots N-1
$$

It then results to this equation: $\mathrm{X}\left(w_{0}\right)=\frac{1}{2} \mathrm{AN}$.

- Goertzel Algorithm (GA)

This approach extracts spectral information from an input frequency signal in a very efficient and quick manner. To compute DFT values, this approach primarily employs twopole IIR type filters. As a result, unlike the DFT (or FFT), which requires a block of data before processing can begin, it is a recursive structure that operates on one incoming sample at a time. The Goertzel filter's IIR structure integrates two 
complex-conjugate poles and simplifies the differential equations computation with only one real coefficient.

The Goertzel Algorithm gives a more precise and accurate analysis of DTMF tones' frequencies, and it is beneficial for memory complexity study. Mathematically, Goertzel Algorithm can be briefly expressed as [20]:

- The computing is done recursively by denoting $\mathrm{n}=$ 0 .. $\mathrm{N}$

$$
V_{k}(n)=2 \cos \left(\frac{2 \pi}{N} k\right) \cdot v_{k}(\mathrm{n}-1)-v_{k}(\mathrm{n}-2)+\mathrm{y}(\mathrm{n})
$$

where $v_{k}(-1)=0, v_{k}(-2)=0$

Where $\mathrm{y}(\mathrm{n})$ is the input, $V_{k}(n)$ is the DFT value which is used to determine the square magnitude of filtering graph, $\mathrm{N}$ is the number of iterations that was recursive, $f_{k}$ is the DFT frequency, $f_{s}$ is the sampled frequency.

- Compute once every $\mathrm{N}$

$$
\begin{gathered}
|\mathrm{y}(\mathrm{k})|^{2}=y_{k}(N) y *_{k}(n) \\
=V_{k} 2(n)+V_{k} 2(\mathrm{~N}-1)-2 \cos \left(2 \pi \frac{f_{k}}{f_{s}}\right) V_{k} 2(\mathrm{~N}) v^{2} \mathrm{k}(\mathrm{N}-1)
\end{gathered}
$$

\section{G. DTMF Decoder}

The decoder table depicts that for each number, a unique row and column frequency is generated, and a 4-bit binary

\begin{tabular}{|c|c|c|}
\hline $\mathrm{S} / \mathrm{N}$ & Key Pressed & Output \\
\hline 1 & $* 0$ & $\begin{array}{l}\text { All Electrical devices connected } \\
\text { powered on }\end{array}$ \\
\hline 2 & $\# 0$ & $\begin{array}{l}\text { All Electrical devices connected } \\
\text { powered off }\end{array}$ \\
\hline 3 & $* n$ & $\begin{array}{c}\text { Device n (any number between 1-4) } \\
\text { is powered on }\end{array}$ \\
\hline 4 & $\# \mathrm{n}$ & $\begin{array}{c}\text { Device n (any number between 1-4) } \\
\text { is powered off }\end{array}$ \\
\hline
\end{tabular}
code word is formed as a result.

TABLE I: DTMF DECODER TABLE

The Arduino Uno microcontroller had been designed so that $*$ denoted powering on devices and \# denoted powering them off. Four sockets were connected to the microcontroller's output ports. As a result, keys 1 to 4 indicated the four respective devices, whereas 0 denoted the total number of devices. Different combinations of mobile keys resulted in a range of operations, as has been shown. The fundamental idea behind this circuit is to use DTMF technology to control appliances like light bulbs and fans. The mobile phone device has a DTMF encoder, and the decoder is an HT9107B IC. A 1nf capacitor is attached to the mobile jack. Two wires make up a mobile jack (Red and black). The decoder IC is linked to the red wire, while the black wire is grounded. When a button on the phone is pressed, a tone is generated, which is deciphered by the decoder IC and delivered to the ATMEGA8 controller. The controller then scans for input and outputs based on the code that has been written to it. When the DTMF controlled home appliances circuit is turned on, the controller examines the inputs on a regular basis. When the number 1 is touched on the DTMF or mobile keypad, the decoder IC decodes the tone and outputs 1 (0001) to the ATmega8 microcontroller, which generates a high output at pin PD0, which is connected to a relay. The relay is utilized to switch the circuit in this case and thus, the light bulb is powered on. The light bulb will be powered off if the received output is 2 . Similarly, if the received input is 3 , the fan will be powered On, whereas if it is 4 , the fan will be powered Off.

\section{RESULTS AND DISCUSSION}

During the presence of electricity at the public power supply, the following results were obtained when the automatic change-over switch was tested; the voltage reading on the multi-meter when used to check for the voltage of the sockets when was $218 \mathrm{~V}$. Only the authorized mobile phone number can call through and control the sockets.

The components were assembled and tested with a multimeter to ensure that they were in good working condition. The pins of the respective soldered segments on the Veroboard were carefully checked for dry joints and shortcircuiting in the connections was tested using a multi-meter. The connecting wires of the various components were thoroughly verified for "continuity" to ensure that no cut-off occurred between the breadboard and the Vero-board.

To test for continuity and confirm that no wires or components were bridging, the soldering of the components was done without the primary components (Arduino Uno, Relays, and GSM Module).

The next step was to verify that the requisite voltages were present at various IC sockets for main components.For the Relay and LCD modules, a 5V typical was validated.Using a voltage regulator (LM317) the 4.2V (required voltage) for the GSM module was confirmed.After that, the major components were joined.The system was tested and implemented by sending various commands (through the user's cell phone) and executing various actions, such as powering On and Off the sockets.. It was noted that before the GSM module would automatically activate its DTMF property, the call has to be connected for about 30 seconds. Also, the Feedback message would be sent after the call or beep.

\section{RESULT ANALYSIS}

The result analysis of this research work arose from the values and observations gotten during the testing operations carried out on this project. The table shown below was the result gotten from the GSM module operation.

TABLE II: KEY ASSIGNED TO DIFFERENT SOCKETS FOR PERFORMING
\begin{tabular}{cc}
\multicolumn{2}{c}{ ON/OFF OPERATIONS } \\
\hline Modes & Current Consumption \\
\hline Power down & $60 \mu \mathrm{A}$ \\
Sleep mode & $1 \mathrm{~mA}$ \\
Standby & $18 \mathrm{~mA}$ \\
Call (GSM 850) & $199 \mathrm{~mA}$ \\
GPRS & $453 \mathrm{~mA}$ \\
SMS Feedback & $2 \mathrm{~A}$ \\
Message &
\end{tabular}




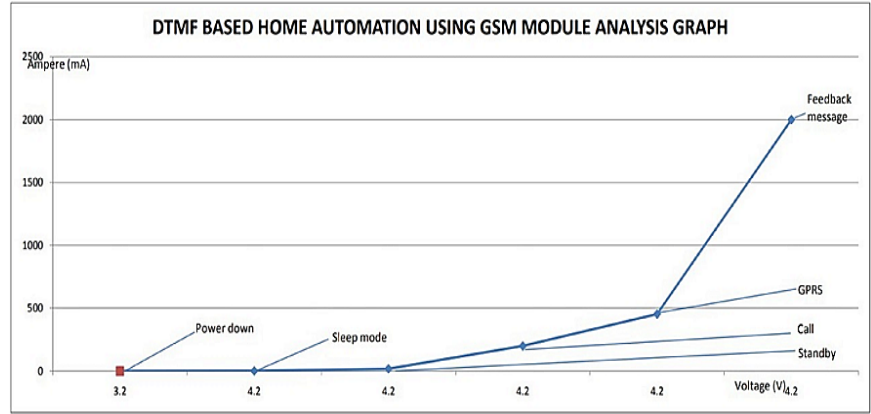

Fig. 7. The graphical analysis of the designed project.

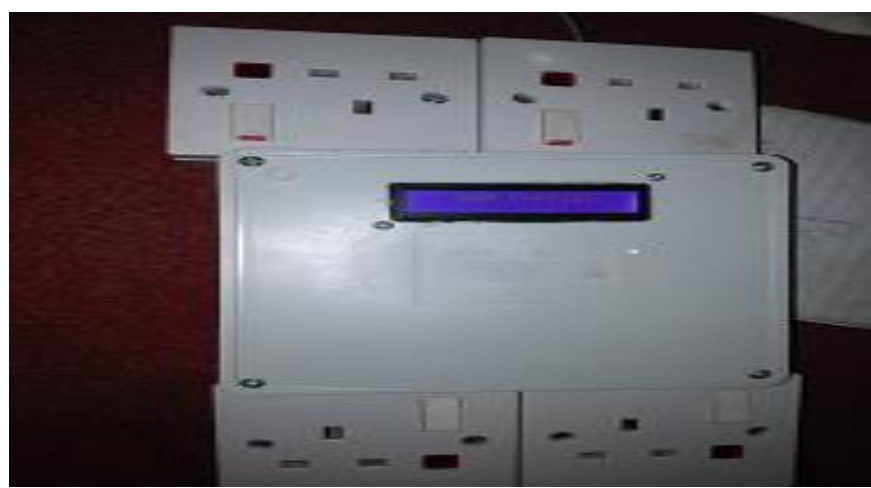

Fig. 8. The complete design of the project.

\section{CONCLUSION}

This research work had presented a DTMF based application for user using any mobile to control appliances without any interface. This project proved to have cleared the uncertainty of whether the task is performed or not on pressing the corresponding key, hence once one beeps the project anytime and the project would give the feedback anytime. Also, it fixed the problem of having cell phone to be fixed in the circuit which makes the system bulk by making use of the GSM Module instead, thereby making the system as small as possible. It also solved the distance problem involved in all other home automation systems, that is one does not need to be home(manual) or close to the home (Bluetooth) before one can control the devices. Finally, with this system, we can aptly save money, time, and energy by monitoring most of our home appliances remotely. From this system, we can also get flexibility, manageability and achieving security. For the physically challenged, this system plays an excessive part.

\section{REFERENCES}

[1] A. Z. Dodd. The essential guide to telecommunications. Prentice Hall PTR, pp. 183, 2002.

[2] V. Darji, W. Dalmet, N. Dharamshi, and S. B. Jee: Cell phone operated remote control using DTMF, International Journal of Computer Applications, vol. 179, no. 35, pp. 32-37, 2018.

[3] S. K. Shareef, N. Shirisha: Efficient automation using DTMF, International Journal of Recent Technology and Engineering, vol. 8, no. 5, pp. 3965-3967, 2020.

[4] Kadepi, M, Sai, B.L, and Sirisha, B. S: A home automation system design using hardware descriptive tools,International Journal of Engineering Research \& Technology, vol. 2, no. 7, 385-393, 2013.

[5] Badamasi, Y.A: The working principle of an Arduino,IEEE.4016, 2-14, 2014.https://ieeexplore.iee.org/document/6997578.

[6] Mallikraj, S. N, Rao, N.T, and Sekhar, C: Studies on utilization of low cost GSM-Bluetooth based home automation system, International Journal of Control and Automation, 10(12), 67-76, 2017.
[7] N. Sriskanthan, F. Tan, A. Karande: Bluetooth-based home automation system, Microprocessors and Microsystems vol. 26, no. 6, pp. 281289.https://doi.org/10.1016/S0141-9331(02)00039-X.

[8] Palaniappan, S., Hariharan, N., T Kesh, N., S, V., \& Deborah S, A Home AutomationSystems - A Study, International Journal of Computer Applications, 116(11), 11-18, 2015.

[9] D. A. Atchyutuni, S. S. Patil, M. S. Varma, K. Chandran, and B. Sreenivas, Raspberry home automation using RFID and GSM, Journal of Xi' an University of Architecture \& Technology, pp. 2806-2813, vol. 12, no. 5, 2020.

[10] R. Hasan, M. Khan, A. Ashek and I.J Rumpa, "Microcontroller based home security system with GSM technology," Open Journal of Safety Science and Technology, vol. 5, pp. 55-62, 2015.

[11] A.Wakas and A. Waseem, "DTMF based home automation," pp. 1-2, 2010.

[12] K. Hassan, R.I. Siddiqui, M.T. Islam, N.A. Siddique, M.E. Uddin "GSM based automatic motor control and protection system," International Journal of Advancements in Research \& Technology, vol. 2, no. 2, pp. 1-4, 2013.

[13] L.M. Bawankule, A.V. Bhalerao, and F.K. Ashwini "Home Automation System using DTMF," International Journal for Scientific Research \& Development| Vol. 7, Issue 01, pp. 56-58, 2019

[14] R. Rucha, L. Jogdand and N. Choudhari, "DTMF based Home Automation System" International Journal of Engineering Science and Computing, Research Article, vol. 7 no. 2, pp. 4328-4331, Feb. 2017.

[15] A.H.M. Asadul, S. Islam and S. Farid "Design and Study of a Home Automation System Using DTMF" pp. 1-32, July 2016.

[16] M. Mamunoor and M.H. Chowdhury, "DTMF bases home appliances control using cell phone," 1st National Conference on Electrical \& Communication Engineering and Renewable Energy, pp. 49-51, Feb. 2014.

[17] H. A. Rangkuti and J. W. Simatupang, "Security lock with DTMF polyphonic tone sensor," International Conference on Automation, Cognitive Science, Optics, MicroElectro-Mechanical System, an Information Technology (ICACOMIT), pp. 119-122, 2015.

[18] S.M. Shirsath, S.R. Popalghat, S.D. Tarate, and Y.S. Pimpale, "Embedded wireless light intensity control using DTMF," International Journal of Innovative Research in Electrical, Electronics, Instrumentation and Control Engineering, vol. 4, no. 5, pp. 57-59, 2016

[19] J. H. Beard, S. P. Given, and B. J. Young, "A discrete Fourier transform based digital DTMF detection algorithm," p. 13.

[20] G. Schmer, "DTMF Tone Generation and Detection: An Implementation Using the TMS320C54x" Application Report, May 2000.

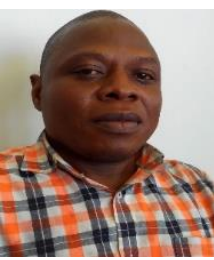

Ayodele S. Oluwole was born in Ekiti State, Nigeria He received the Bachelor's degree (2003) in Electrical and Electronics Engineering from the University of Ado-Ekiti, Nigeria, and Master degree (2010) in Electrical and Electronics Engineering (Communication option) from the Federal University of Technology, Akure, Nigeria. He is a Ph.D. degree holder in Electronic Engineering, University of KwaZulu-Natal, South Africa, 2018. His research interests include Smart Antenna, antenna theory and design, array signal processing, Electromagnetic theory, and Microwave Engineering.

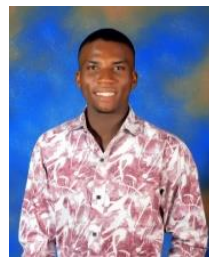

O. P. Odekunle was born into the family of Dr and Mrs Olusogo Odekunle of Osu, Osun State, Nigeria some twenty one years ago. He bagged his Bachelor of Engineering degree with a Second Class Upper Honours in Electrical and Electronics Engineering from the Federal University Oye-Ekiti in February 2020.

He had his Undergraduate Internship at the British American Tobacco, Ibadan between July, 2018 and January, 2019. He equally had his Graduate Engineering Internship at the department of Engineering works at the Cocoa Research Institute of Nigeria between March 2020 and March 2021. He is a Graduate member of the Nigerian Society of Engineers as well as the International Association of Engineers.

Oluwamurewa is currently focusing application for MSc in the Fall 2022 Academic Session. His research interests are Home Automation, Microgrids, Smartgrids, Renewable Energy systems, Power Systems, and Control Systems. 


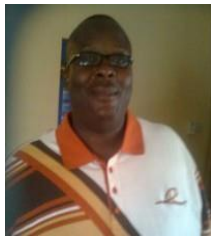

Eniola Olubakinde is a Lecturer at Federal Polytechnic Ile-Oluji, Nigeria.

$\mathrm{He}$ is currently pursuing his $\mathrm{PhD}$ degree in Power

System, Kharkov City, Ukraine. 